\title{
Research on service management of manufacturing enterprises based on quality housing
}

\author{
Xueyuan Wang ${ }^{1}$, Meixin $\mathrm{He}^{1, *}$, and Mingxing Chen ${ }^{1}$ \\ Harbin University of Science and Technology, School of economics and Management, 150080, \\ Harbin, Heilongjiang Province, China
}

Keywords: Manufacturing enterprise, servitization, managing method, House of Quality.

\begin{abstract}
Based on house of quality concept, the relation between servitization strategy and strategic elements were confirmed through grey relational analysis method. Accordingly, the specific elements characteristics of manufacturing enterprise management core - talents \& team and relationship, knowledge resources and flowing, information infrastructure and treatment methods, and organization structure and management were illustrated in three servitization stages - product servitization enlarging, servitization capability continuously improving and servitization integration and innovation. According to elements characteristics, the strategic targets for different servitization stages were brought forward, and four strategic elements specific managing methods were further offered for different servitization stages. The research can offer decision references for manufacturing enterprise to confirm element character and servitization stage, and give effective support to confirm management key points and methods of servitization in manufacturing enterprises at different stages.
\end{abstract}

\section{Introduction}

Manufacturing enterprises servitization has become an important strategic choice to realize the development goal of Chinese manufacturing industry in the 13th Five-Year Plan and to implement Made-in-China 2025. Manufacturing enterprise servitization is conducive to improving the profitability of enterprises, enhancing the intangible competitiveness of enterprises, enhancing customer loyalty, and promoting the sustainable development of enterprises. Therefore, all countries are actively promoting the transformation and development of servitization in manufacturing enterprises. However, the current research on manufacturing enterprises servitization mainly focuses on the necessity, influencing factors, types or modes. There are few studies on the management methods of how to realize servitization transformation, which can not provide direct and effective operation

"Corresponding author: 1169465306@qq.com 
guidance for manufacturing enterprises. In addition, the current research rarely distinguishes the stages and types of manufacturing enterprises servitization, and mainly puts forward servitization measures and strategies around the manufacturing enterprises as a whole. However, manufacturing enterprises in different stages have different management contents and management modes of servitization. The lack of research results in this field has affected the effectiveness of practice guidance on manufacturing enterprises servitization. Therefore, on the basis of confirming the management core of servitization, designing detailed management methods has important theoretical research value and practical guiding significance.

\section{Determining the management core of manufacturing enterprises servitization}

Enterprise strategic transformation is not just a competitive strategy adjustment, but also includes other elements that make up the enterprise strategy (Damanpour and Gopalakrishnan, 2013). The essence of strategic transformation is to "reconstruct" the production factors that can form strategic characteristics (Oliver \& Park, 2014). The overall transformation of the enterprise should be achieved through the adjustment of the strategic elements of the enterprise. Smith \& Grimm (2016) believes that resource endowments will have an impact on the strategic transformation ways. Therefore, the management core of servitization in manufacturing enterprises should be determined on the basis of analyzing and determining the strategic elements and resources.

\subsection{The construction of house of quality for manufacturing enterprises servitization}

House of Quality (HOQ) is a basic design tool of quality deployment. It reflects the correlation between customer demand and quality functional elements, and it is helpful for enterprises to produce competitive products. Scholars have improved it and applied it to different fields. Tian (2015) applied it to the analysis and evaluation of the relationship between the quality of distribution channels and capability. Wang et al. (2012) improved the method and applied it to the economic quality analysis of service industry, the structural equation method was used to determine the correlation matrix, and the economic House of Quality in the service industry was proposed., and then the method was further used to analyze the project collaboration efficiency (Wang et al., 2014) .

Based on the House of Quality evaluation idea, a House of Quality is constructed between strategic elements and manufacturing enterprise servitization strategy, and the management core of servitization is brought forward, the relationship between characteristic elements and servitization strategy and the feasibility that characteristic elements can contribute to the competitive advantage of manufacturing enterprises are revealed and the general idea of action plan is also proposed, which can be seen in Figure 1.

Servitization strategy of manufacturing enterprises mainly includes determining the location of servitization in the enterprise (That is to clarify the role of service business in the process of creating economic value of enterprises: auxiliary function, parallel development or leading role, etc.), determining the improvement ways of manufacturing enterprise competitiveness (Self-improvement and expansion, resource and service integration, etc.) and determining the business model of manufacturing enterprise (Customized, one-stop, etc.) Manufacturing enterprise form a clear servitization strategy by determining the above three aspects. 


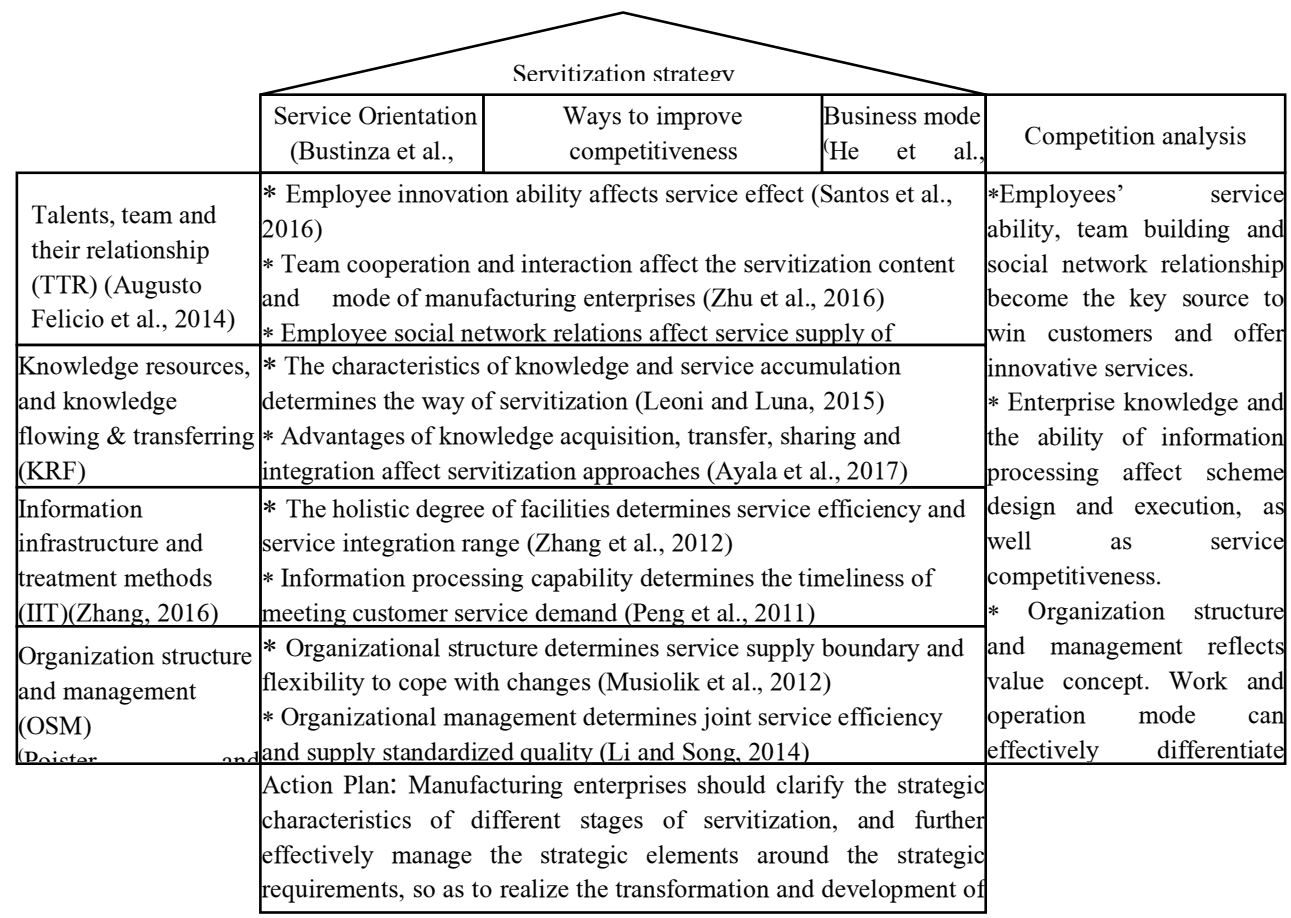

Fig. 1. HOQ model of strategic elements and servitization.

The strategic elements are the keys for manufacturing enterprise to effectively differentiate their competitors and enhance their core competence. Therefore, in the process of manufacturing enterprise servitization, we should focus on the strategic direction of enterprise servitization, focus on the management of strategic elements, promote the planning and step-by-step implementation of servitization strategy, and improve the effect of servitization transformation.

\subsection{Relation determination in HOQ based on grey relational analysis method}

Based on theoretical analysis of the influence of strategic elements on servitization strategy, quantitative analysis is made by expert scoring and grey correlation analysis, and the correlation degree between them is calculated individually. The correlation degree is shown in Table 1.

Table 1. Correlation degree of strategic elements and servitization strategy.

\begin{tabular}{cccc}
\hline $\begin{array}{c}\text { Four strategic } \\
\text { elements }\end{array}$ & $\begin{array}{c}\text { Service } \\
\text { Orientation }\end{array}$ & $\begin{array}{c}\text { Ways of competitiveness } \\
\text { improvement }\end{array}$ & $\begin{array}{c}\text { Business } \\
\text { model }\end{array}$ \\
\hline TTR & 0.57 & 0.77 & 0.47 \\
KRF & 0.43 & 0.65 & 0.41 \\
IIT & 0.38 & 0.47 & 0.42 \\
OSM & 0.44 & 0.41 & 0.89 \\
\hline
\end{tabular}

According to the results of correlation analysis, the correlation degrees are all above 0.3 , which shows that all of the four strategic elements can influences service strategy, while TTR has much closer relation with service location and ways of competitiveness 
improvement, and KRF has much closer relation with ways of competitiveness improvement, and OSM has much closer relation with business model. Manufacturing enterprises have different service strategic objectives under different resource conditions. Manufacturing enterprises form specific servitization strategy based on the determination of service location, competitiveness enhancement methods and business models. In this process, enterprises should pay attention to the utilization and arrangement of human, knowledge, information and organizational management resources, and effectively implement the servitization strategy.

\section{Design of management method for manufacturing enterprise servitization}

According to the state of the four strategic elements, the manufacturing enterprise servitization can be divided into the product servitization enlarging stage, servitization capability continuously improving stage and servitization integration and innovation stage.

Firstly, when the human resources, team skills and knowledge reserves are mainly concentrated in the field of product technology, and the service information infrastructure construction has just started in short period, the enterprise focuses on integrating internal resource and guaranteeing the development of service business. Therefore, the strategic goal of manufacturing enterprises in this stage is to provide related services for customers around existing leading products. This stage can be called the product servitization enlarging stage. Secondly, with the implementation of servitization, the service knowledge of enterprises is becoming more and more abundant, teamwork is closer and more effective than before, and it can effectively guide different enterprises to carry out related activities for different products. Manufacturing enterprises have established effective cooperative relationships with their stakeholders, and can jointly provide customers with convenient, rich and diverse services, and the service response speed is also greatly improved. This stage is the service capability continuously improving stage. The main task is to continuously improve service quality, service scope, service impact, service knowledge reserve and service information processing speed. Finally, manufacturing enterprises have formed a complete service system and network. Around service knowledge base, they can collect and quickly integrate various network resources accordingly to service demand, and provide complete service solutions to achieve one-stop system services for customers' demands in various industries. The main strategic tasks of manufacturing enterprises at this stage are value creation and service reputation enhancement. The enterprises acquire more service demand and at the same time they can flexibly integrate resources, effectively realize the connection of service supply and demand, and continuously relying on external strength to innovate various service contents and methods. This stage can be called the service integration and innovation stage.

\subsection{Management of manufacturing enterprises in product servitization enlarging stage}

Manufacturing enterprises that have entered the stage of servitization transformation initially should adopt a gradual servitization transformation method, explore and develop possible value-added services around the leading products and services of manufacturing enterprises, find feasible value-added points of servitization, and accurately determine the direction of servitization transformation, and integrate internal resources and form knowledge reserves around the service direction.

(1) Train service personnel and establish servitization discussion team. 
(2) (2) Construct servitization knowledge base and obtain service knowledge.

(3) Collect information on servitization and construct information infrastructure.

(4) Integrate internal resource and guarantee servitization resource.

In this stage, enterprises mainly focus on collecting service information and accumulating service knowledge, establishing and improving own service knowledge base and information infrastructure, and enhancing the personnel adaptability for servitization, developing single-point servitization by discussing feasible servitization items and integrating internal resources, so as to make good preparation for establishing chain service mode based on improving the relevance and matching degree between servitization items.

\subsection{Management of manufacturing enterprises in servitization capability continuously improving stage}

After the servitization of manufacturing enterprises developing to a certain stage, its products will become the basic guarantee of servitization supply, product sales become auxiliary business. Manufacturing enterprise needs to continuously improve the quality and characteristics of servitization. The enterprise service system will connect with more service businesses, service demanders and suppliers, and the service contents will be continuously optimized to form chained servitization.

(1) Train professional service team.

(2) Integrate servitization knowledge and offer knowledge transfer service.

(3) Enhance information standardization and interface compatibility.

(4) Improve the influence and response ability of manufacturing enterprises.

In this stage, enterprises focus on the establishment and development of professional service teams, and can separate servitization from the product field, can effective use and integrae the stakeholder resources to provide holistic and personalized manufacturing services, and they continuously open knowledge base to stakeholders to form consensus concept in service mode and content. In addition, enterprises focus on the docking of service information facilities and the mining of service demand to continuously improve service diversity and service response speed, to cultivate and develop chain service mode.

\subsection{Management of manufacturing enterprises in servitization integration and innovation stage}

In the process of improving service advantages and characteristics, manufacturing enterprises actively explore multi-field cooperation or expand existing services to different fields to form a horizontal service system. Focusing on the horizontal service system, manufacturing enterprises should continuously gather resources and form the ability to quickly provide services in different fields through network relationship; on the other hand, the manufacturing enterprise services are extended in depth, and around the service advantages, the organic matching of the upper and lower chain services is formed to provide a complete one-stop service.

(1) Construct relation management team.

(2) Integrate knowledge and make innovation.

(3) Use external information based on cloud technology.

(4) Improve integration, docking and controlling ability.

In this stage, manufacturing enterprises should focus on relying on network information technology and using external resources to quickly gather and integrate resources and provide one-stop system services and guarantee the organic coordination among different resources and subjects, so as to provide network services for a wide range of service demanders. 


\section{Conclusion}

In this paper, by using the method of house of quality analysis and grey relational degree calculation method, the TTR, KRF, IIT and OSM as four strategic elements affecting the implementation of servitization strategy and competitive advantage of manufacturing enterprises are revealed, and the overall action plan of manufacturing enterprises servitization is proposed. Introducing contingency thought, it reveals the characteristics of the four types of strategic elements under the three stages of product servitization enlarging, servitization capability continuously improving and servitization integration and innovation, and the service strategy - service orientation (providing and improving self-service around products, relying on stakeholders to achieve service leading, utilization of internal and stokeholds' resources to offer service), competitiveness improvement methods (improvement of self-service capability, integrating stakeholders to provide differentiated services, integrating external resources to provide systematic services) and business models (point service, chain service, network integration service) under different servitization stages are analyzed. On this basis, the specific management methods with three stages are brought forward. The management key points are compared and analyzed. And the integrated servitization management model is proposed. The study can provide effective decision support for the servitization strategy implementation of manufacturing enterprises. In the future, panel data can be used for statistics and analysis to make the conclusions more objective. In addition, case study can be introduced to further study in the specific path for servitization transformation of a certain type of manufacturing enterprise, so as to provide systematic and more detailed method support for manufacturing enterprises servitization.

\section{References}

1. Augusto Felicio, J., Couto, E., and Caiado, J. (2014) 'Human capital, social capital and organizational performance', Management Decision, Vol. 52 No.2, pp.350-364.

2. Damanpour, F. and Gopalakrishnan, S. (2013) 'Theories of Organizational Structure and Innovation Adoption: The Role of Environmental Change', Journal of Engineering and Technology Management, No.15, pp.5-24.

3. Guenther, M., Guenther, P., Bell, S.J., and Robins G.L. (2016) 'It's the Strength of the Ties: How Multiplex Social Networks Among Frontline Employees Drive Service Performance', Looking Forward, Looking Back: Drawing on the Past to Shape the Future of Marketing, pp.149-155.

4. He, Z., Wu, Y. and Jang, J. (2013) 'Analyzing,Evaluating and Measuring the Interaction and Integration between Producer Services and Strategic Emerging Industries', China Soft Science,No.5, pp.129-143.

5. Kastalli, I V. and Looy , B V. (2013) 'Servitization: Disentangling the impact of service business model innovation on manufacturing firm performance', Journal of Operations Management, Vol. 13 No.31, pp.169-180.

6. Leoni. and Luna. (2015) 'Adding service means adding knowledge: an inductive single-case study', Business Process Management Journal, Vol. 21 No.3, pp.610-627.

7. Ayala, Néstor Fabián., Paslauski, C. A., Ghezzi, A., and Frank, Alejandro Germán. (2017) "Knowledge sharing dynamics in service suppliers $\$ " involvement for servitization of manufacturing companies', International Journal of Production Economics, Vol. 193, pp.538-553. 